\title{
Serviço Social e pandemia: desafios e perspectivas para a atuação no sociojurídico
}

\section{Social Work and covid-19 pandemic: challenges and perspectives for action in the Socio-Legal}

\author{
Silvia da Silva Tejadas ${ }^{a}$ \\ (D) https://orcid.org/0000-0002-6667-699X \\ Maíz Ramos Junqueira ${ }^{a}$ \\ (D) https://orcid.org/0000-0003-1481-1800
}

Resumo: $\mathrm{O}$ artigo discute a pandemia, na conjuntura brasileira, e suas repercussões para o trabalho do(a) assistente social no sociojurídico - Poder Judiciário, Ministério Público e Defensoria Pública. Debate os efeitos das contrarreformas na condição de trabalhador(a) do(a) assistente social e na precarização das políticas públicas. Situa o trabalho remoto, as tensões engendradas por mecanismos administrativos de contenção de custos e de ampliação do trabalho virtual e formas de resistência desenvolvidas.

Palavras-chave: Sociojurídico. Pandemia. Trabalho remoto.
Abstract: This article discusses the covid-19 pandemic, in Brazilian context, and its repercussions for the work of the social worker in Socio-Legal - Judiciary, Public Ministry and Public Defender's Office. Debate the effects of counter-reforms in the conditions of social workers and on the precariousness of public policies. It situates remote work and the tensions engendered by administrative mechanisms to contain costs and expand the forms of virtual work, and forms of resistance by professionals.

Keywords: Socio-legal. Pandemic. Remote work. 


\section{Introdução}

m vírus surgido no final do ano de 2019, em Wuhan, na China, vem desacomodando o mundo. O Sar-Cov-2, o novo coronavírus, chegou ao Brasil em período impreciso. Em 3/2/2020, o Ministério da Saúde brasileiro emitiu o Decreto no 188 , no qual qualificou a situação como Emergência em Saúde Pública de Importância Nacional (Espin), em decorrência da infecção humana causada pelo novo coronavírus. Desde então, vive-se no país o alastramento da pandemia que, no período de conclusão deste artigo, tinha contaminado mais de 4 milhões de pessoas e ocasionado em torno de 150 mil mortes.

A pandemia agregou, ao combalido Brasil, novas mazelas e acentuou desigualdades preexistentes. Alterou a vida de toda a população, fazendo com que indicações de isolamento social e rotinas de higienização fizessem parte do cotidiano. Como em um caleidoscópio, é possível analisar a conjuntura do país com o advento da pandemia sob diversos aspectos, dependendo das lentes utilizadas. Neste artigo, articulam-se dois eixos de análise: a corrosão das políticas públicas, responsáveis por materializar os direitos sociais positivados e aqueles demandados na arena pública, bem como suas repercussões no sociojurídico, especialmente junto ao Poder Judiciário, ao Ministério Público e à Defensoria Pública e, por conseguinte, nos processos de trabalho do(a) assistente social.

O tema é desenvolvido em duas partes. A primeira, voltada para os elementos sócio-históricos da conjuntura, em especial no tangente às diretrizes de Estado para o enfrentamento da pandemia e da crise instalada. A segunda discute o trabalho do(a) assistente social no sociojurídico nessa contextura, vislumbrando efeitos na sua condição de trabalhador(a), bem como na atuação em direção à garantia e à ampliação de direitos humanos. 


\section{Governo Bolsonaro: entre o negacionismo da pandemia e a ampliação das contrarreformas}

A miríade de condicionantes presente na conjuntura atual brasileira dificulta uma análise sumária da realidade. Todavia, não há como discutir o trabalho do(a) assistente social, inclusive no sociojurídico, sem sinalizar o contexto no qual se insere. Assim, inicia-se pela macrorrealidade, sobre a qual diversos(as) autores(as) discutem a crise mundial do capitalismo, desnudando que o "ciclo virtuoso" se esgotou e que o sistema vem vivenciando sucessivas crises, dado seu caráter incontrolável e voltado para a expansão e a acumulação. Esse processo é visível nos efeitos com relação ao trabalho, pois, se não pode ser eliminado, já que é a força capaz de valorizar o capital, sob o comando do capital financeiro, suas condições vêm sendo barbarizadas, por meio da terceirização de todas as posições laborais, a informalidade, o trabalho intermitente, o análogo à escravidão, a chamada "uberização", enfim, um conjunto de formas que aprofundam a superexploração (Antunes, 2020).

Ao lado da crise estrutural do capitalismo, a conjuntura brasileira se desenrola de modo singular, favorecendo a exacerbação da exploração da classe trabalhadora. Para compreender esse cenário, é preciso, em uma rápida retrospectiva, recuar até 2016. O golpe, articulado a partir de um conjunto de forças que interagem na cena brasileira - as jurídicas, as midiáticas, as legislativas e as elites brasileiras — , derrubou do poder a presidenta Dilma Rousseff. Em consequência, a condução da política econômica e social que desde os governos Lula, com diferentes nuances, pode ser reconhecida como de cunho neodesenvolvimentista, também chamada de conciliatória, sofreu profundos revezes, afetando o papel do Estado.

A passagem do governo Dilma até a eleição de Jair Bolsonaro teve um interstício marcante sob a égide de Michel Temer. Em dois anos, Temer realizou um conjunto de contrarreformas que abalaram as condições de proteção do trabalho e dos direitos sociais erigidos na Constituição Federal de 1988. O governo Temer foi responsável, a partir de 
seu programa Uma Ponte para o Futuro, que recuperou completamente a agenda neoliberal, por pelo menos três reformas: trabalhista, sindical e terceirizações. Deixou pendente a reforma da Previdência e instituiu a Emenda Constitucional no 95/2016.

O conjunto das reformas desregulamenta as relações de trabalho no país, dilapidando o arcabouço da Consolidação das Leis Trabalhista, de 1943. A exemplo, a Lei no 13.467 , de 2017, trata a venda da mercadoria força de trabalho não mais como uma relação entre pessoas, mas entre coisas, subtraindo a perspectiva historicamente construída pelas lutas da classe trabalhadora de que essa mercadoria é distinta, pois está imersa em relações desiguais. As bases da reforma são a flexibilização da jornada e da remuneração, o trabalho intermitente (iguala a mercadoria trabalho a outra alugada como um serviço) e autônomo (desconstituindo direitos do[a] trabalhador[a]). Institui negociação descentralizada, diminuindo a condição de barganha dos(as) trabalhadores(as), previsão de demissão coletiva sem negociação sindical (Carvalho, 2017). Facilita as formas de demissão, sem necessidade de negociação com o sindicato, por acordo com $80 \%$ do Fundo de Garantia do Tempo de Serviço (FGTS) e sem direito ao seguro-desemprego.

Esses efeitos nas formas de contratação, na remuneração e na segurança do(a) trabalhador(a) articulam-se à reforma sindical, que, de modo sumário, impacta na diminuição dos freios estatais e sindicais aos processos de mercadorização da força de trabalho. Sobretudo, destacam-se a validação do negociado sobre o legislado, o estrangulamento financeiro dos sindicatos e a possibilidade de negociação individual (Krein, 2018). O enfraquecimento das condições de organização, do poder dos(as) trabalhadores(as) e a dilapidação de seus direitos, alimentando a desproteção social, têm repercussões no conjunto das políticas públicas, pois impactam no financiamento da própria seguridade.

A partir do mirante que observa os direitos dos(as) trabalhadores(as), pode-se conjecturar que a sua desconstituição afeta o Serviço Social de duas formas: na condição de trabalhador(a) do(a) assistente 
social que vende sua força de trabalho e na atuação, especificamente no sociojurídico, objeto deste artigo. Os(as) assistentes sociais com registro ativo junto às estruturas do conjunto CFESS/Cress somam 199.622 em 2020. ${ }^{1}$ Destes, 355 estão no Ministério Público, conforme levantamento realizado pelo Serviço Social da unidade do Paraná, para fins de instruir o debate do VIII Encontro Nacional do Serviço Social no Ministério Público. ${ }^{2}$

Não há dados atualizados acerca das formas de contratação dos(as) assistentes sociais no Brasil. Porém, pesquisa realizada em 2005 fornece os seguintes indicadores: trata-se de uma categoria majoritariamente feminina (97\%); 38\%, naquela época, tinham entre 35 e 44 anos; portanto, hoje, estariam próximos(as) da aposentadoria, sendo fortemente afetados(as) pela contrarreforma previdenciária; 78,16\% atuavam na esfera pública estatal, 55,68\% dos quais com vínculo estatutário (CFESS, 2005). No caso do Ministério Público, o levantamento citado aponta que a maioria dos(as) profissionais foi contratada por concurso público, à exceção do Rio de Janeiro, onde há apenas um concursado em meio a setenta profissionais comissionados(as), sendo essa possivelmente uma tendência em expansão na instituição (Paraná, 2020). Considerando que o(a) assistente social é contratado(a), comumente, por organizações da sociedade civil ou pelos órgãos de Estado, todas as mudanças em curso, no tangente à desproteção dos(as) trabalhadores(as), também colocam assistentes sociais na berlinda quanto à condição de reprodução da própria força de trabalho. Por outra via, a partir do exercício profissional, o(a) assistente social se confronta com os efeitos deletérios das reformas para as classes que vivem do trabalho, pois aumentam a pobreza e a desigualdade social.

Conforme informação colhida junto ao CFESS, trata-se do número de inscrições ativas em 30 set. 2020.

2 O formulário de coleta foi elaborado pela Comissão Organizadora do Evento (assistentes sociais do MP do Paraná) e as informações foram preenchidas com vistas a instruir o debate do VIII Encontro Nacional do Serviço Social no Ministério Público. 
$\mathrm{Na}$ toada do desmonte dos direitos positivados, ainda na gestão Temer e de modo articulado às contrarreformas no âmbito do trabalho, tem-se a Emenda Constitucional no 95/2016, a qual prevê um novo regime fiscal que impõe limite de gastos ao governo federal por vinte anos, com apenas o reajuste inflacionário do ano anterior, desconsiderando taxas de crescimento econômico e demográfico dos próximos anos. Para Mariano (2019, s/p),

além da suspensão do projeto Constituinte de 1988, o novo regime fiscal revela uma clara opção por uma antidemocracia econômica, inviabilizando a expansão e até mesmo a própria manutenção de políticas públicas para reservar dinheiro público e garantir o pagamento das obrigações assumidas pelo governo federal brasileiro perante os credores da dívida pública.

Desse modo, a Ponte para o Futuro desemboca em um projeto de Estado mínimo que alimenta o capital financeiro e direciona o fundo público para os interesses do capital, no qual as políticas públicas se (des)universalizam, focalizam e precarizam ao mesmo tempo. $O$ governo de Michel Temer cria as bases de sustentação desse modelo que será ampliado por Jair Bolsonaro, eleito em 2018, com o aprofundamento das contrarreformas trabalhista, sindical, previdenciária e, no momento em que este artigo é redigido, encontra-se na pauta a reforma administrativa. Vale ressaltar que todos esses processos de desmonte de direitos não ocorrem isentos de lutas da sociedade, desde greves, ocupações de universidades, manifestações de rua, até as formas de manifestações nas redes sociais, notadamente diante das transformações provocadas pelo coronavírus nas interações sociais. Salienta-se, contudo, que as formas de resistência desenvolvidas até o momento, ainda que relevantes e necessárias, não têm sido capazes de conter a torrente.

A eleição de Bolsonaro se insere em um contexto de ascensão de projetos autoritários e retrógrados, nominados por alguns(mas) autores(as) como "populistas". Para Mounk (2019, p. 16), por exemplo, o que 
tem alimentado tais projetos é certa descrença da população para com a democracia liberal e seus resultados.

A desilusão do cidadão com a política é coisa antiga; hoje em dia, ele está cada vez mais inquieto, raivoso, até desdenhoso. Faz tempo que os sistemas partidários parecem paralisados; hoje, o populismo autoritário cresce no mundo todo, da América à Europa e da Ásia à Austrália. Não é de hoje que os eleitores repudiam esse ou aquele partido, político ou governo; agora, muitos deles parecem estar fartos da democracia liberal em si.

Nessa toada, as análises sobre o governo Bolsonaro estão sendo feitas ao mesmo tempo que se descortina seu governo. É possível afirmar que o projeto por ele representado foi eleito com base no pensamento retrógrado, amparado nas igrejas neopentecostais, nos grupos militares e paramilitares de direita e nas elites conservadoras nacionais, ávidas por conduzir o projeto neoliberal sem concessões. Portanto, embora se diga que se trata de um "(des)governo", compreende-se que o governo Bolsonaro está ancorado por explícito projeto ideológico, político e econômico. Por outro lado, suas forças são heterogêneas - neopentecostais, militares, milicianos, olavistas, ${ }^{3}$ grupos econômicos representados por Paulo Guedes - e, por vezes, colidem entre si.

Além do modelo econômico adotado, já explicitado, o grupo no poder se pauta por estratégias e táticas de "guerra de ódio", de fake news, de criação de narrativas reacionárias sobre a sociedade e o comportamento. Pode-se dizer que o governo Bolsonaro concilia economia ultraliberal com um Estado teológico (teologia da prosperidade), amparado na despolitização da sociedade, como traz Chaui (s/d).

A reunião ministerial de 22 de abril de 2020, em plena ascensão da pandemia no país, que veio a público por meio do Supremo Tribunal Federal, deixa patente essas dimensões, assim como as dissidências

3 Olavistas: expressão utilizada pela designar um dos apoiadores do presidente, Olavo de Carvalho. 
internas ao projeto. Digladiaram-se, a partir de uma visão negacionista da pandemia, o núcleo duro econômico - representado por Guedes e pelos dirigentes dos bancos estatais - , os militares em busca de um plano de reconstrução nacional e a agenda de valores reacionários, voltada para os costumes e para a organização social — representada, especialmente, por Damares Alves e o então ministro da Educação, Abraham Weintraub. Entre outras mazelas, a reunião descortinou a guerra do governo federal aos governadores e prefeitos que buscassem enfrentar a pandemia de modo organizado, baseados nas orientações sanitárias e nas experiências internacionais, capitaneadas pela Organização Mundial da Saúde, no sentido de conter a transmissão exponencial do novo coronavírus e minimizar sua letalidade.

Os(as) assistentes sociais do sociojurídico palmilham essa realidade a partir dos seus postos, como sujeitos que vivem a perda de direitos e como profissionais que se deparam com as inúmeras expressões da desigualdade e das formas de resistência da população.

\section{Assistentes sociais no sociojurídico: entre o assujeitamento acrítico e a resistência coletiva}

O sociojurídico, nos debates da categoria profissional, aglutina amplo leque de profissionais, desde aqueles(as) que atuam nas instituições componentes do sistema de justiça (Poder Judiciário, Ministério Público e Defensoria Pública) até os(as) que interagem a partir da Segurança Pública e da Justiça e Direitos Humanos (unidades prisionais, socioeducação e Forças Armadas). Dada a diversidade de experiências nessas instituições, será dado especial relevo aos desafios vividos junto ao Poder Judiciário e ao Ministério Público, chão da vivência cotidiana das autoras e com base nas experiências delas, e, quando possível, à Defensoria Pública.

Desde que se anunciou o avanço da pandemia, as instituições do sistema de justiça, de modo geral, mantiveram atividades presenciais de urgência e deslocaram as demais para o ambiente remoto. Nesse 
contexto, situa-se um grande desafio para os(as) assistentes sociais nesse período.

É interessante observar que o ambiente virtual promovido pela pandemia vem se associando, no decorrer dos meses, a mudanças que estão sendo introduzidas por essas instituições no âmbito da administração dos processos de trabalho. Movimentos que vinham sendo desenvolvidos nos últimos anos, caracterizados pela visão produtivista, na qual o trabalho técnico é mensurado por prazos e metas, com foco em resultados, pela redução de custos, pela conformação de um(a) profissional polivalente, capaz de atuar concomitantemente em diferentes frentes, foram intensificados nesse momento. A pandemia, de certa forma, tornou-se ambiente para a antecipação de pressupostos que estão embutidos na contrarreforma administrativa nas instituições do sociojurídico.

Evidenciam-se desdobramentos relativos à qualidade do trabalho técnico ofertado à população e outros atinentes à condição de trabalhador(a) do(a) assistente social. São diversas as tendências identificadas no real, algumas sutis, outras explícitas. Um dos nós críticos que se apresentam é a tentativa de substituição, em alguns espaços, do trabalho do(a) técnico(a) pelo de outros(as) profissionais de nível médio a partir de atividades roteirizadas. Outra tendência que vem se acentuando nas instituições que compõem o sociojurídico é a de terceirização do trabalho técnico. Tal movimento se insere no contexto de desmantelamento dos serviços públicos sob o discurso do contingenciamento orçamentário. Seus efeitos concretos são o aumento da informalidade, diminuição salarial, aumento da jornada de trabalho, alta rotatividade entre os(as) trabalhadores(as), perda dos direitos trabalhistas, entre outros aspectos (Alves, 2017), contribuindo, portanto, para os processos de precarização das relações de trabalho.

É importante salientar ainda que, no contexto da pandemia, os(as) assistentes sociais são demandados(as) a utilizar meios virtuais para a realização de suas atividades de trabalho. No Ministério Público, são solicitadas avaliações institucionais e, no Poder Judiciário, a realização da 
perícia social, que diz respeito à avaliação de situações familiares/individuais. Do mesmo modo, na Defensoria Pública, os(as) assistentes sociais são instados a realizar atendimentos por meio de whatsapp e e-mail.

As experiências de trabalho remoto, no Ministério Público e no Poder Judiciário em nível estadual, estavam bem no início no período anterior à pandemia, embora já se vislumbrasse que se tratava do "trabalho do futuro" nessas instituições. Diante da urgência do distanciamento social, os(as) profissionais foram direcionados(as) para o trabalho remoto sem qualquer preparação, utilizando-se, em geral, de recursos próprios para a realização das atividades laborais. Os(as) profissionais acabaram, na maior parte dos casos, por utilizar seus notebooks, telefones celulares, pacotes de dados da internet, rede wi-fi, energia elétrica, entre outros recursos, para atender às requisições institucionais nesse período.

O trabalho remoto, conforme ensina Antunes (2020), tende a ser mantido após a pandemia, pois se mostra vantajoso do ponto de vista das instituições empregadoras. Nesse sentido, o ambiente pandêmico tem possibilitado um verdadeiro "laboratório" de experiências, tanto na esfera pública quanto na privada, resultando em maior exploração da força de trabalho e diminuição dos seus custos.

No que diz respeito aos(às) trabalhadores(as), contudo, os efeitos do trabalho remoto tendem a ser deletérios: diminuição das relações solidárias e coletivas no espaço de trabalho (justamente o espaço que possibilita, segundo o autor, "a consciência das reais condições de trabalho"), distanciamento dos sindicatos, tendência à eliminação de direitos, diluição das fronteiras entre "tempo de trabalho e tempo de vida", intensificação do trabalho feminino, entre outros aspectos (Antunes, 2020). Com jornadas de trabalho extenuantes e enfrentando a diminuição das redes de apoio, visto que a pandemia alterou o funcionamento não só das instituições, mas também dos grupos familiares e comunidades, os(as) trabalhadores(as) vivenciam processos intensos de precarização de suas condições de vida e de trabalho, com repercussões, inclusive, quanto ao adoecimento físico e mental. Os(as) assistentes sociais não são poupados 
dessa realidade, na medida em que o trabalho remoto se desenrola em meio ao cuidado de filhos e idosos que coabitam, sobrecarregando, em especial, as mulheres.

Se a pandemia escancarou a crise do capital e as desigualdades estruturantes da sociedade brasileira, não foi diferente quanto às contradições presentes nas relações de trabalho dos(as) assistentes sociais do sociojurídico. Apesar das limitações impostas para o exercício das atividades em uma difícil conjuntura, esses(as) profissionais seguem, em geral, sendo exigidos(as) no que diz respeito ao alcance de metas e prazos, muitas vezes com demandas de tarefas que se tornam difíceis ou mesmo inviáveis no cenário vivido. Tal situação escancara relações históricas de subalternidade e de assédio moral vivenciadas em diversos desses espaços, convocando os(as) profissionais à reflexão sobre o seu trabalho em instituições verticalizadas e de tendência autoritária, visto que com parcos espaços de participação e democratização. Instiga ainda a construção de alianças com operadores(as) do direito e parceiros(as) de outras áreas do conhecimento embalados(as) por ideários democráticos.

No caso dos(as) profissionais inseridos no Poder Judiciário, a demanda pela realização de perícia social, principal requisição institucional, em meio à pandemia desconsidera limitações concretas - por um lado, dificuldades para a realização de atendimentos presenciais; por outro, problemas de acesso da população usuária aos recursos necessários para o atendimento virtual, bem como as orientações do Conselho Federal de Serviço Social (CFESS). Salienta-se que o posicionamento do CFESS é contrário à realização de perícia social por meio eletrônico, conforme a nota da Comissão de Orientação e Fiscalização (2020), que afirma a necessidade de garantia da qualidade ética e técnica, bem como do sigilo profissional.

Conforme diz Fávero (2020, p. 10-11),

se o estudo social implica em [sic] conhecer e analisar a realidade socioeconômica, de trabalho, habitacional/territorial, cultural, familiar, dos sujeitos, de maneira aprofundada, para assegurar o oferecimento de subsídios 
qualificados à decisão judicial e/ou à defesa, registrados em algum tipo de documento, não é possível fazê-lo por meio remoto.

Em algumas unidades do Ministério Público dos estados, toada semelhante ocorreu, com a preferência pela realização de avaliações institucionais por meio virtual, em relação ao presencial, inclusive com a regulamentação dessa medida para o trabalho das áreas técnicas para o período pós-pandemia. Na Defensoria Pública, a realidade não é distinta, na medida em que os(as) profissionais são requisitados(as) à realização de avaliações sociais fazendo uso de meios virtuais, o que não é viável pelas razões éticas e técnicas expostas.

De modo comum, entre esses espaços, pode-se afirmar que o Serviço Social, profissão das ciências sociais aplicadas, nos processos avaliativos dos quais toma parte, se utiliza de um conjunto de instrumentos que permitem a aproximação com a população, usuários(as), técnicos(as) e dirigentes de serviços, de modo que a observação, a entrevista semiestruturada, a visita institucional, entre outros, requerem essencialmente presencialidade. Este é elemento constitutivo de grande parte das atividades do(a) assistente social, especialmente aquelas que se propõem a avaliar condições e modos de vida das famílias, bem como a qualidade de serviços públicos ou privados prestados à população.

É meritório destacar que em todos os espaços do sociojurídico e, em especial os que são objeto deste artigo, têm havido o empenho dos(as) profissionais no sentido de executar as atividades possíveis neste momento, como, por exemplo, reuniões e encontros com a rede de serviços, contribuições em processos de formação/capacitação, estudos avaliativos sobre políticas públicas com dados disponíveis ou coletados de modo remoto, atendimentos à população sem cunho avaliativo/pericial. Ainda, de modo criativo, em algumas unidades do Ministério Público, foi alavancada a ampliação da atuação no direito difuso e coletivo, como na análise dos planos de contingência da política de assistência social, entre outras iniciativas desse quilate. 
Nessa perspectiva, é fundamental que seja assegurada a autonomia profissional para a definição das possibilidades e limites do trabalho a ser realizado na conjuntura da pandemia e após, com vistas à garantia dos princípios éticos da profissão, respeito à privacidade, sigilo profissional e qualidade dos serviços prestados à população.

Além da autonomia para o exercício profissional, observa-se que a pandemia e o contexto que a cerca incidem para a consolidação de transformações nesse espaço sócio-ocupacional na condição dos(as) profissionais como trabalhadores(as). No âmbito do Ministério Público, há estados com diversos(as) profissionais com contratos como cargo em comissão e cedidos(as) de outros órgãos, conforme levantamento já citado (Paraná, 2020). Também há estados que estagnaram o número de profissionais concursados(as) nos últimos anos. No Poder Judiciário, apresenta-se a realidade das perícias contratadas, nas quais o(a) assistente social é remunerado(a) por documento produzido, por vezes com tabela de valor inferior à de outros(as) profissionais. $\mathrm{O}(\mathrm{a})$ assistente social contratado(a) para uma tarefa pontual, com produto específico, não conhece a instituição com maior profundidade, suas dinâmicas nem idiossincrasias. Dessa maneira, essa forma de contratação pode favorecer o trabalho alienado, uma vez que está desenraizado da conjunção institucional e de um sistema de garantia de direitos.

É na contextura descrita, marcada pela tensão provocada por novas e antigas demandas e desafios, que os(as) assistentes sociais do sociojurídico se movimentam cotidianamente. A ausência de uma leitura macroscópica, que leve em consideração os aspectos estruturais, conjunturais e contraditórios do real, tende a favorecer a captura da subjetividade desses(as) profissionais, resultando em processos de assujeitamento acrítico. Vale lembrar que os(as) assistentes sociais, na qualidade de trabalhadores(as) assalariados(as) (Iamamoto, 1998), estão sujeitos(as) aos processos de alienação inerentes às relações de trabalho, situação que requer uma leitura que contemple a perspectiva da totalidade na apreensão do conjunto da vida social. 
O trabalho do(a) assistente social, contudo, também é permeado pelo caráter contraditório que marca não somente a profissão, mas o terreno institucional e a própria sociedade. A contradição, desse modo, engendra o surgimento de formas de resistência no próprio trabalho cotidiano.

O cenário da pandemia, que ameaça a vida e escancara as desigualdades sociais, explicitou as contradições vivenciadas pelos(as) assistentes sociais nas instituições do sociojurídico. É no embate diário e na ação miúda do cotidiano profissional que é possível encontrar a potência para a conformação de práticas que fortaleçam os caminhos para a resistência, a luta coletiva e a emancipação humana.

Vale destacar a experiência dos(as) assistentes sociais judiciários no Rio Grande do Sul, que optaram pelo caminho da construção coletiva em tempos de pandemia. Tais profissionais, mediante a criação de um grupo de trabalho junto ao Sindicato dos Servidores da Justiça do RS (Sindjus RS), somam reflexões, aprendizados e conquistas, como, por exemplo, a vedação, pela Corregedoria Geral de Justiça, de realização de visitas domiciliares no período da pandemia e a elaboração do documento Protocolos de atendimento do Serviço Social judiciário no contexto de pandemia pela covid-19 (GTASS, 2020).

Outra conquista importante do referido grupo de trabalho foi a realização, em setembro de 2020 , por meio virtual, da $1^{\text {a }}$ Reunião dos Assistentes Sociais Judiciários da Região Sul. Tal evento reuniu profissionais dos Tribunais de Justiça do Rio Grande do Sul, Paraná e Santa Catarina e possibilitou a discussão de pautas e estratégias comuns de trabalho no contexto da pandemia. Esse movimento segue na esteira de experiência já consolidada do Serviço Social no Ministério Público, que realiza encontros nacionais bianuais desde 2006. Em 2020, o encontro ocorreria no Paraná e, não sendo possível a presencialidade, serão realizados encontros virtuais nos estados, regiões e no âmbito nacional. Tais encontros, além do debate em torno da identidade e direção do Serviço Social no Ministério Público, têm sido impulsionadores da produção teórica e do compartilhamento de experiências com a elaboração de 
artigos. ${ }^{4}$ Na Defensoria Pública também há movimentos de articulação coletiva nacional dos(as) técnicos(as) de áreas não jurídicas, tendo ocorrido em 2019 o III Congresso Brasileiro de Atuação Interdisciplinar nas Defensorias Públicas. Desse modo, observa-se o uso de estratégias de articulação intracategoria e com outras formações, essenciais ao debate, reflexão e construção coletiva dos rumos do Serviço Social e da defesa e garantia de direitos humanos nessas instituições.

\section{Palavras finais: o caminho está no coletivo}

A pandemia do novo coronavírus colocou a humanidade em xeque: cogita-se em um "novo normal", prospectam-se possibilidades de alterações nos rumos das vivências em sociedade, inclusive em torno das questões ambientais. Apesar dessas conjecturas, o futuro carrega algo de imperscrutável, dado o aumento das desigualdades, da exacerbação da intolerância em diversas dimensões, da superexploração do trabalho sob a égide do capital financeiro.

Sabe-se que todas essas tensões e disputas de projetos societários serão carreadas para as instituições do sociojurídico em alguma medida. O próximo período será, sem dúvida, desafiador aos(às) assistentes sociais, pois serão instados(as) a agir na defesa dos direitos da população no acesso à justiça; nas disputas judiciais, em meio a tentativas de culpabilização e criminalização dos indivíduos pelas decorrências das desigualdades e da sociabilidade capitalista; no acesso a políticas públicas, em contexto de precarização, de onde também se descontextualizam as situações, mirando apenas a intencionalidade de gestores(as) e trabalhadores(as). São lutas que ultrapassam a categoria profissional! Ao mesmo tempo, provocam os(as) assistentes sociais a assumirem posição no fazer cotidiano, pois é também na microesfera que se apresentam contradições e

4 Em 2020, inclusive, foi realizado amplo levantamento nacional acerca das condições de trabalho e da intervenção profissional, porém não publicado a tempo deste artigo. 
armadilhas de negação de direitos. Por outra via, na condição de trabalhadores(as), há o desafio da incorporação às lutas gerais da classe em todos os âmbitos em que ela se processa; e, como categoria profissional, continuar trilhando o caminho que é caro ao Serviço Social na defesa intransigente da democracia, da autonomia, da liberdade e dos direitos humanos.

\section{Referências}

ALVES, Giovanni. Terceirização: o futuro do trabalho no Brasil. Trabalho, Educação e Saúde, Rio de Janeiro, v. 15, n. 2, p. 337-339, ago. 2017. Disponível em: http://www. scielo.br/scielo.php?script=sci_arttext\&pid=S1981-77462017000200337\&lng=en\&nrm =iso. Acesso em: 16 out. 2020.

ANTUNES, Ricardo. Coronavirus: o trabalho sob fogo cruzado. São Paulo: Boitempo, 2020.

CARVALHO, Sandro Sachett. Uma visão geral sobre a reforma trabalhista. Política em foco. Mercado de Trabalho, n. 63, out. 2017. Disponível em: http://repositorio.ipea.gov.br/ bitstream/11058/8130/1/bmt_63_vis\%C3\%A3o.pdf. Acesso em: 12 out. 2020.

CHAUI, Marilena. O retorno do teológico-político. São Paulo: Universidade de São Paulo, s/d. Disponível em: https://www.ces.uc.pt/bss/documentos/o_retorno_do_teologico.pdf. Acesso em: 15 out. 2020.

CONSELHO FEDERAL DE SERVIÇO SOCIAL (CFESS). Assistentes sociais no Brasil: elementos para o estudo do perfil profissional. Brasília: CFESS, 2005.

FÁVERO, Eunice. Introdução: aproximaç̃̃es ao contexto da pandemia, da realidade social e do exercício profissional da/o assistente social. O Exercício Profissional da/o Assistente Social em espaços Sócio-ocupacionais do Sociojurídico no Contexto da Pandemia e do Teletrabalho: Contribuições ao Debate, São Paulo Núcleo de Estudos e Pesquisa sobre Crianças e Adolescentes (NCA), Boletim n. 1, maio 2020.

GTASS - Grupo de Trabalho dos Assistentes Sociais Judiciários do Sindicato dos Servidores da Justiça do RS. Protocolos de atendimento do Serviço Social judiciário no contexto de pandemia pela Covid-19. Porto Alegre: Sindjus RS, 2020. Mimeografado.

IAMAMOTO, Marilda Villela. O Serviço Social na contemporaneidade: trabalho e formação profissional. São Paulo: Cortez, 1998.

KREIN, José Dari. O desmonte dos direitos, as novas configurações do trabalho e o esvaziamento da ação coletiva: consequências da reforma trabalhista. Tempo Social, 
São Paulo, v. 30. n. 1, jan./abr. 2018. Disponível em: https://www.scielo.br/scielo. php?pid=S0103-20702018000100077\&script=sci_arttext. Acesso em: 12 out. 2020.

MARIANO, Cynara Monteiro. Emenda constitucional 95/2016 e o teto dos gastos públicos: Brasil de volta ao estado de exceção econômico e ao capitalismo do desastre. Rev. Investig. Const, Curitiba, v. 4. n.1, jan/abr. 2017. Disponível em: https://www.scielo.br/ scielo.php?script=sci_arttext\&pid=S2359-56392017000100259. Acesso em: 12 out. 2020.

MOUNK, Yascha. O povo contra a democracia: por que nossa liberdade corre perigo e como salvá-la. São Paulo: Companhia das Letras, 2019.

PARANÁ. Ministério Público do Paraná. Comissão Organizadora do VIII Encontro Nacional do Serviço Social no Ministério Público. Formulário para levantamento de dados. Paraná: Ministério Público, 2020. Mimeografado.

\section{Sobre as autoras}

Silvia da Silva Tejadas - Doutora em Serviço Social e assistente social do Ministério Público do Rio Grande do Sul.

E-mail: siltejadas@terra.com.br

Maíz Ramos Junqueira - Doutora de Serviço Social e assistente social do Poder Judiciário do Rio Grande do Sul lotada na Comarca de Guaíba.

E-mail: maizramosjunqueira@gmail.com 